\title{
REMOTE SENSING FOR ESTIMATION OF INTENSITY AND EXTENT OF PLANT RESIDUE COVER
}

\author{
Richa Prajapati $^{1, *}$, Debashis Chakrborty, Saurav Saha, V.K. Gupta and R.N. Sahoo \\ ${ }^{1}$ Division of Agricultural Physics, ICAR-Indian Agricultural Research Institute, New Delhi 110012-richaprajapati13@gmail.com
}

\author{
Commission III, WG III/10
}

KEY WORDS: Crop residue cover, Hyperspectral remote sensing, Cellulose Absorption Index, Reflectance

\begin{abstract}
:
Left-over crop residue on the surface is a measure of tillage intensity and soil management, and is an integral part of the conservation agriculture practice. Remote sensing can be successfully used to monitor the large area crop residue cover which is otherwise difficult through the conventional way, provided the spectrally similar crop residues and soil can be suitably differentiated. Hyperspectral reflectance $(350-2500 \mathrm{~nm})$ of various quantities of crop residue cover over red soil was measured with varying moisture contents in the residue. A broad spectrum near $2100 \mathrm{~mm}$ was identified for dry residue, which was not recorded in soil spectra. This could possibly be linked to the cellulose-lignin content. The cellulose absorption index (CAI) was evaluated for crop residue cover with moderate to good correlations, with strong dependency on the residue water content. A few narrow bands were identified to characterize both the cellulose-lignin (i.e. the CAI) and the water content, and could be incorporated in on-board multispectral sensors for regional estimation of crop residue over the soil surface.
\end{abstract}

\section{INTRODUCTION}

The critical need to match the increasing world population and food production gave rise to sustainable land management strategies. Thus practicing Conservation Agriculture (CA) at a large scale has been proposed as a propitious approach to reduce soil degradation and to maintain an healthy environment. CA is a set of three management practices- crop diversification, reduced or no tillage and crop residue retention. However adoption of any one or set of these practices to benefit farmers depends upon the socioeconomic, climatic and biophysical conditions in which they are employed. Conservation Tillage (CT), an important aspect of CA, is an ecological approach that leaves $30 \%$ of the soil surface covered with crop residue which is renewable source and its improper use can aid accelerated erosion and environmental pollution (CTIC, 2004).

Food and Agriculture Organisation of the United Nations promoted maintenance of crop residue or plant litter to protect topsoil from water and wind erosion for sustainable cropping systems. Crop residue is defined as the plant left over in the fields the harvest and thrashing. To protect the soil surface from erosion, retention of plant litter is considered as an effective measure. According to Lal, the total amount of principal nutrients contained in crop residues ranges from 40 to $100 \mathrm{~kg}$ tons $^{-1}$ (Lal, 1995). Hence quantification of crop residue is necessary to evaluate $\mathrm{CT}$ practices and determining the temporal land cover changes. The advantages to leave crop residue on the soil for conservation of agriculture are reduction in run off volumes and nutrients into rivers, addition of nutrients to the soil, improvement in the soil structure and it also affects carbon sequestration. It is considered as the "greatest source of soil organic matter" (Tisdale, Nelson, \& Beaton, 1985). The standard technique to estimate crop residue cover used earlier by the U.S. Department of AgricultureNatural Resources Conservation Service (USDA-NRCS) was using a line-transect method which proved to be tedious and impractical method (Morrison, Huan, Lightle, \& Daughtry,
1993). Other methods such as visual estimation, point intercept, meter stick and photographic techniques were also found to be subjective, prone to errors and unsuitable for large spatial coverage.

Remote sensing proved its potential as an alternative to conventional methods to detect crop residues since 1975, major challenge being to differentiate bare soil and residues (Gausman et al., 1975). Several experiments carried in fields and laboratory investigated spectral and spatial detail for accurate and rapid mapping of crop residue cover. Various indices are found in the literature for quantitative evaluation of crop residue such as Brightness Index, Cellulose Absorption Index, Normalised Difference Index and Crop Residue Index Multiband. These indices were based on analysis of multispectral or hyperspectral data or spectroradiometric ground based measurements carried over different soil and residue types (Biard \& Baret, 1997; Major, Larney, \& Lindwall, 1990; Mcnairn \& Protz, 1993). Few past and current remote sensing satellites capable of estimating total crop residue cover include EO-1 Hyperion, Worldview-3, the Advanced Spaceborne Thermal Emission and Reflection Radiometer (ASTER), Landsat $5 \mathrm{TM}, \mathrm{ETM}+$ and OLI. Out of these, Landsat imagery proved to be the best available one due to the presence of SWIR band which is sensitive to crop residue detection with moderate spatial resolution and 8-day revisit rate.

The reflectance spectra of soils and crop residue are often similar and are not easily distinguishable in visible and near infrared wavelength region due to no specific spectral feature in $0.4-1.1 \mu \mathrm{m}$ region and reflectance of residue may be more or less than that of soil. To address the difficulty of discriminating the two, concept of absorption feature is used. It was observed that in plants three narrow absorption features occurring at 1760,2100 and $2300 \mathrm{~nm}$ are associated with presence of nitrogen, cellulose and lignin concentrations (Curran, Dungan, \& Peterson, 2001). These are not recognisable in fresh vegetation and wet crop residue spectra. Also these are not discernible in dry soils however minerals present in the soil can 
cause additional features. According to Murray and Williams, the absorption spectrum is related to sample's absorbing molecules and is largely affected by their composition, also dipoles magnitude, interaction between different molecules or functional groups on a molecule influence the absorption spectrum (Murray \& Williams, 1988). It was observed that $2100 \mathrm{~nm}$ broad absorption band appears in compounds having $\mathrm{OH}$ group such as cellulose, sugars and starch. Also dry plant residue show $2100 \mathrm{~nm}$ absorption band in its reflectance spectra hence Daughtry et al. proposed Cellulose Absorption Index (CAI) which is based on three bands separated over $50 \mathrm{~nm}$ (Daughtry, 2001) and is defined as the relative intensity of the absorption feature near $2100 \mathrm{~nm}$. Hence to capture these absorption features and classifying crop residue from the background soil, the reflectance spectra in contiguous and narrow bands of electromagnetic spectrum is needed. The technological advances in hyperspectral remote sensing enhanced the ability for identification and quantification of crop residue through its unique capability of acquiring complete reflectance spectrum in $350-2500 \mathrm{~nm}$ region. This can be acquired using lab experiments, airborne or satellite platform.

In this study, lab experiments were carried out over red soil and various quantities of crop residue with water content ranging from dry to saturate condition for both soil and mixed scene using spectroradiometer.

\section{MATERIALS AND METHODS}

\subsection{Laboratory Experiment Design}

2.1.1 Soil lab spectra: The Spectroradiometer was used to acquire the reflectance spectra of soil from $350-2500 \mathrm{~nm}$ wavelength region at an interval of $1 \mathrm{~nm}$. Primarily a $30-\mathrm{cm}$ square Spectralon reference panel which behaves as the lambertian surface was used to create a reference spectrum for spectroradiometer. Red soil collected from Saravanampatti, Coimbatore was tested in the laboratory and its spectral reflectance was recorded. Before carrying the experiment this soil was oven-dried at $105^{\circ} \mathrm{C}$ for 2 days and crushed to pass a 2$\mathrm{mm}$ screen. Then it was placed in a sample tray and was saturated with water. It was drained for $1 \mathrm{hr}$ and dried sequentially till air-dry at room temperature, and reflectance was measured in each stage. The water content of the soil was calculated as the Relative Water Content (RWC) which ranges from 0 (oven-dried) and $\mathrm{RWC}=1$ (saturated). It was also expressed in the form of percentage moisture as seen in the graph.

2.1.2 Lab spectra of soil and crop residue: Crop residue of rice was collected from agricultural fields after harvest. The crop residue were cut in segments and dried at $70^{\circ} \mathrm{C}$ for $48 \mathrm{hrs}$. The mass of crop residue required to completely cover the sample tray with one layer was determined $\left(\mathrm{M}_{\mathrm{R}}\right)$. The crop residue was added to the soil by increasing the weight and measuring it in the units of $\mathrm{M}_{\mathrm{R}}$ from 0.3 to 1.5 . These crop residues were then removed and weighed before placing them in mesh bags for saturation which was further drained for $2 \mathrm{~h}$. These drained wet rice residues was reweighed and added to the soil surface. These steps of drying the crop residue and measurements of the spectra were repeated. RWC was calculated as the ratio of water content of residue and maximum water content.

The reflectance spectrum for crop residue was plotted against the wavelength and as a function of different RWC as well as residue cover. CAI was calculated as:

$$
\mathrm{CAI}=100 \times\left(0.5\left(\mathrm{R}_{2.0}+\mathrm{R}_{2.2}\right)-\mathrm{R}_{2.1}\right)
$$

where $R_{2.0}, R_{2.2}$ and $R_{2.1}$ denote reflectance over $10 \mathrm{~nm}$ bands centered at $2030 \mathrm{~nm}, 2100 \mathrm{~nm}$ and $2210 \mathrm{~nm}$ respectively. Figure 1 shows the sample trays with rice residue placed over the soil in various proportions demonstrated with $\mathrm{M}_{\mathrm{R}}$

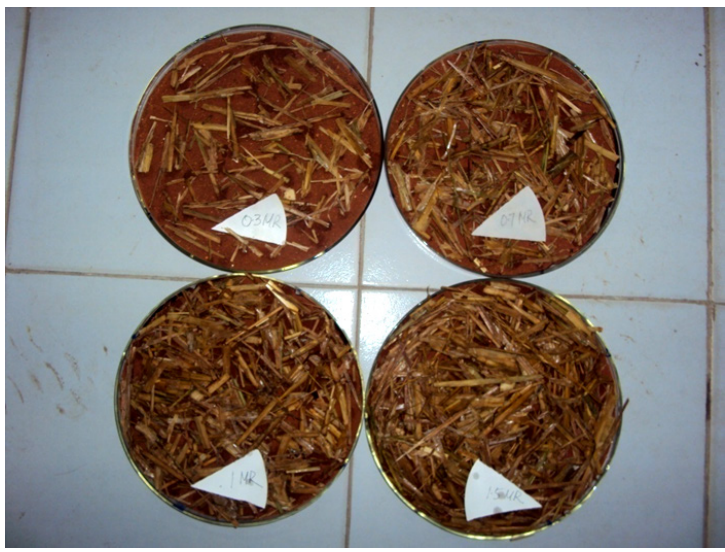

Figure 1 Sample trays containing soil+ rice residue for experiment

As the residue content increased, it covered the soil to the extent which confers that spectral reflectance for $1.5 \mathrm{M}_{\mathrm{R}}$ would have less effect from the background soil. A much closer view can be seen in figure 2 below.

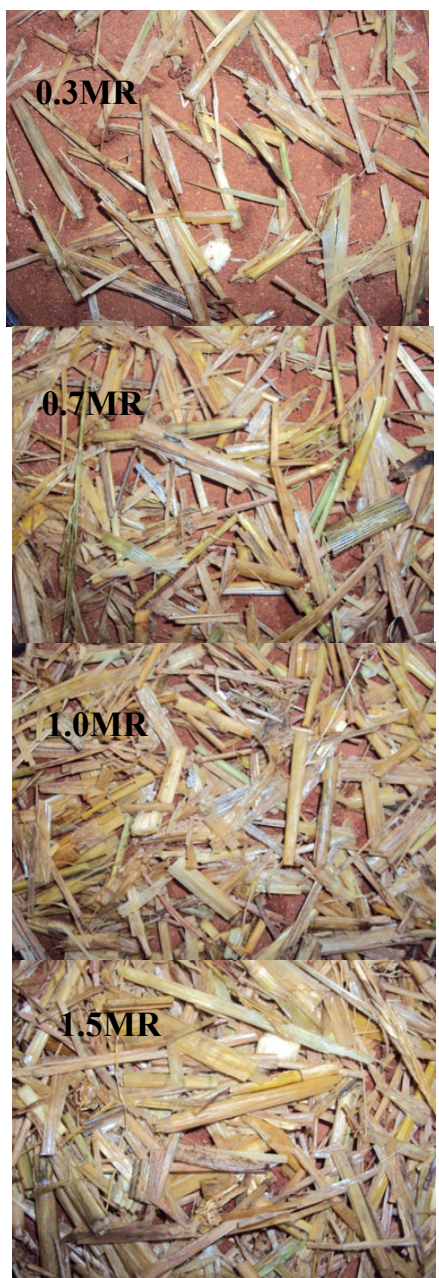

Figure 2 Zoomed view of crop residue cover 


\section{RESULTS AND DISCUSSION}

\subsection{Reflectance spectra of soils}

The soil spectra tested in the laboratory for different moisture conditions ranging from saturated to dry can be seen in figure 3 below. The reflectance values varied widely as the percentage moisture content increased. The oven-dried soil shows the reflectance of about $0.4-0.5$ in shortwave infrared region. As the water content in the soil increased, the reflectance factor decreases to as low as $0.2-0.3$ for saturated soil compared to dry soil with reflectance ranging from $0.7-0.6$. The major dips seen in the figure at $1400 \mathrm{~nm}$ and $1900 \mathrm{~nm}$ were water absorption dips which got widened and deeper for the saturated soil. An absorption dip at $2200 \mathrm{~nm}$ was associated with mineral content in the soil, which diminished in the wet soil. The moisture content effect on the reflectance of the soil was noticeable in near infrared and shortwave infrared region rather than visible region.

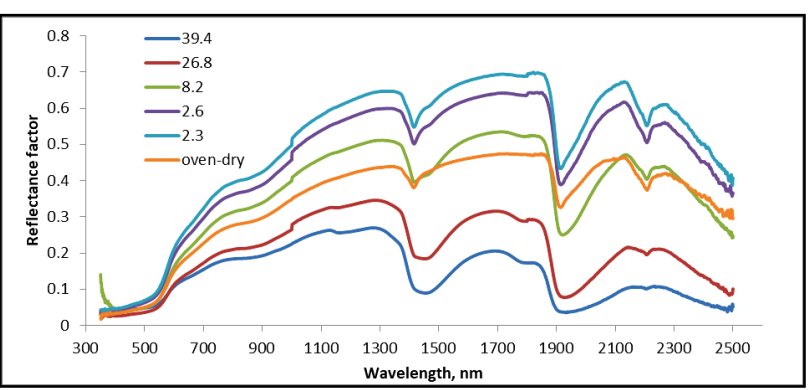

Figure 3 Reflectance spectra of red soil against wavelength for various percentage of moisture content

\subsection{Reflectance spectra of mixed scene}

Different amounts of rice residue were placed over air-dried red soil and reflectance was plotted for four RWC against wavelength region. The residue cover used was $0.3 \mathrm{MR}, 0.7$ $\mathrm{MR}, 1.0 \mathrm{MR}$ and $1.5 \mathrm{MR}$. Here MR is $6.44 \mathrm{gm}$ of crop residue that completely covered the tray. As shown in figure 4 , the reflectance spectra of rice residue from dry to saturated condition exhibited similar pattern in terms of changes with wavelength. The spectra increased gradually for all proportions of residue cover in visible region $(400-700 \mathrm{~nm})$, increased from $700-1400 \mathrm{~nm}$ for unsaturated residue cover (for saturated residue cover, water dips were observed) and by and large reduced in shortwave infrared region (1400-2400nm). In near infrared region, for dry crop residue cover, the reflectance increased with increase in quantity of residue cover. However in shortwave region, the spectra of varying $M_{R}$ merged. It was observed that as the water content increased in the residue, the reflectance reduced for all wavelengths over different $M_{R}$ of the residue. The water absorption bands at $1450 \mathrm{~nm}$ and $1960 \mathrm{~nm}$ can be clearly seen in the figure. These absorption features were more prominent for water saturation compared to dry condition. In the figure 5(a), the depth of water absorption bands was very low due to low water content in crop residues; however, the soil contained some moisture.

It can be inferred from the graph that as the residue covers increased, the reflectance of the residue also increased except in the saturation condition. For RWC-1.0, the reflectance increased as the residue content increased in the visible and near infrared region; however it reduced in shortwave infrared region and showed an inverse trend. The absorption at $2100 \mathrm{~nm}$ band appeared as broad absorption feature in all spectra from dry to wet residue cover. The feature represents $-\mathrm{OH}$ bond in lignin and cellulose molecules which intensified with increase in crop residue cover. This broad absorption feature remained obscured for the saturated residue cover.

The calculated CAI values showed a linear relationship with the crop residue cover and were also related to the RWC of the residue. It was clear from figure 5 that CAI had mostly positive values for all the crop residues except the saturated condition. The linear relationships along with slope, intercept and correlation coefficients are given in table 1 . It can be observed that the $\mathrm{r}^{2}$ values were greater than 0.7 for RWC ranging from .03 to 1.0 . The $\mathrm{r}^{2}$ values for saturated and near saturated crop residue cover were less than the dry crop residues.

It was noted that CAI values increased as the amount of residue cover above the soil increased irrespective of water content (RWC) in the residue. Also, the CAI values were analysed against relative water content for all residue cover as well as for the soil (figure 6). It was found that CAI values were negative for soils. Hence CAI proved to be reliable indicator for separating red soils and rice residues (Daughtry, McMurtrey, Chappelle, Hunter, \& Steiner, 1996). As seen in figure 6, the dashed line at $\mathrm{CAI}=-1$ separated the soil from rice residue regardless of the moisture content of the soil.

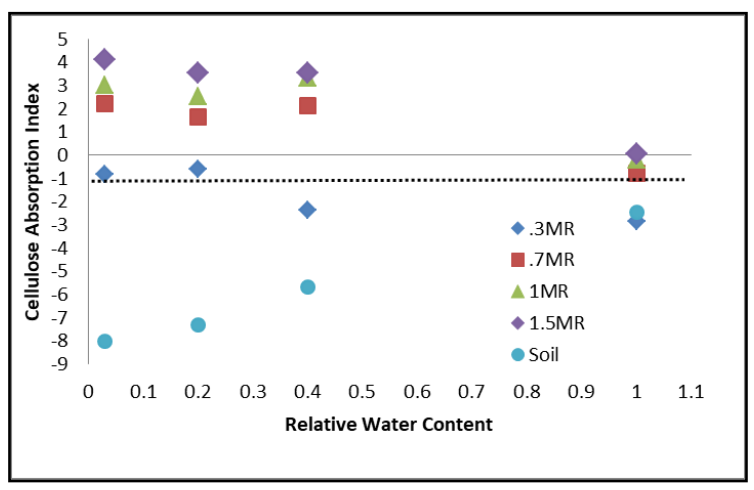

Figure 6 CAI and RWC plotted for crop residue and soil

In figure 6 it can be visualised that for dry residues and soil, CAI values are well separated. This separation reduces as the water content increases and approaches towards saturation. As the residue cover and soil gets saturated, the differences diminished. This is well related to the conclusions drawn by (Daughtry, 2001; Nagler, Daughtry, \& Goward, 2000).

\section{CONCLUSION}

This experiment was carried mainly to analyse the reflectance spectra of mixed scene of soil and crop residue and to separate these two using absorption bands and Cellulose Absorption Index. It was observed that presence of moisture in red soil reduced the reflectance. For mixed scenes, the reflectance factor increased with increase in the residue cover for RWC (in residues) ranging from 0 to 1 . This accounted to the brighter appearance of the scene as the fresh residue cover increased. The increase in residue cover was found related linearly to the CAI values with high correlation coefficients. The CAI also proved to be a robust indicator to separate soil and residue cover as the soil had negative CAI values in comparison to mostly positive values of residue. Hyperspectral remote sensing allowed in quantifying the residue cover, which can be extended by using optical data in synergy. 


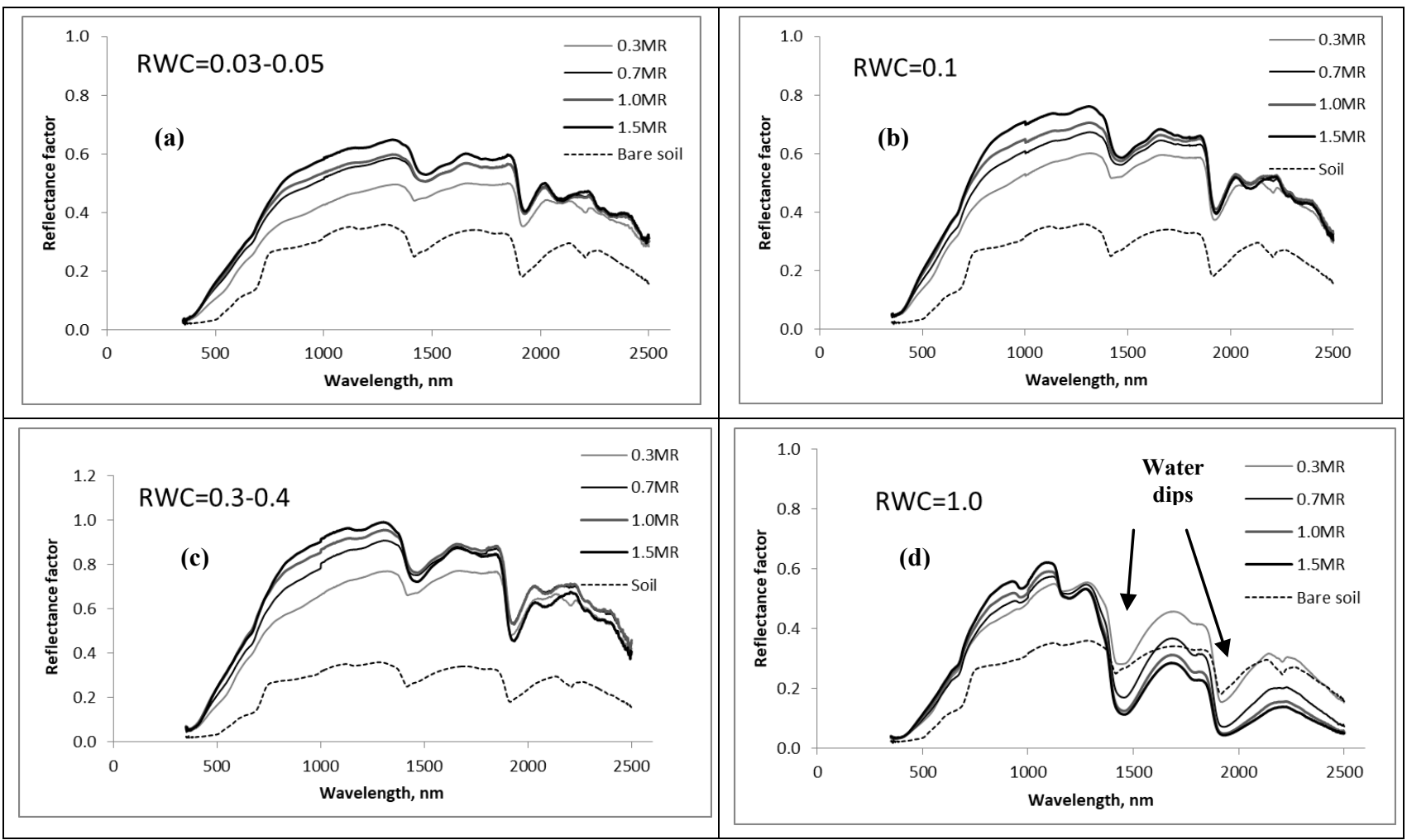

Figure 4 Reflectance spectra for different mass of rice residue placed over red soil for (a) RWC $=0.03-0.05$ (dry) (b) $\mathrm{RWC}=0.1$ (c) $\mathrm{RWC}=0.3-0.4$ (moist) and (d) $\mathrm{RWC}=1.0$ (saturated)

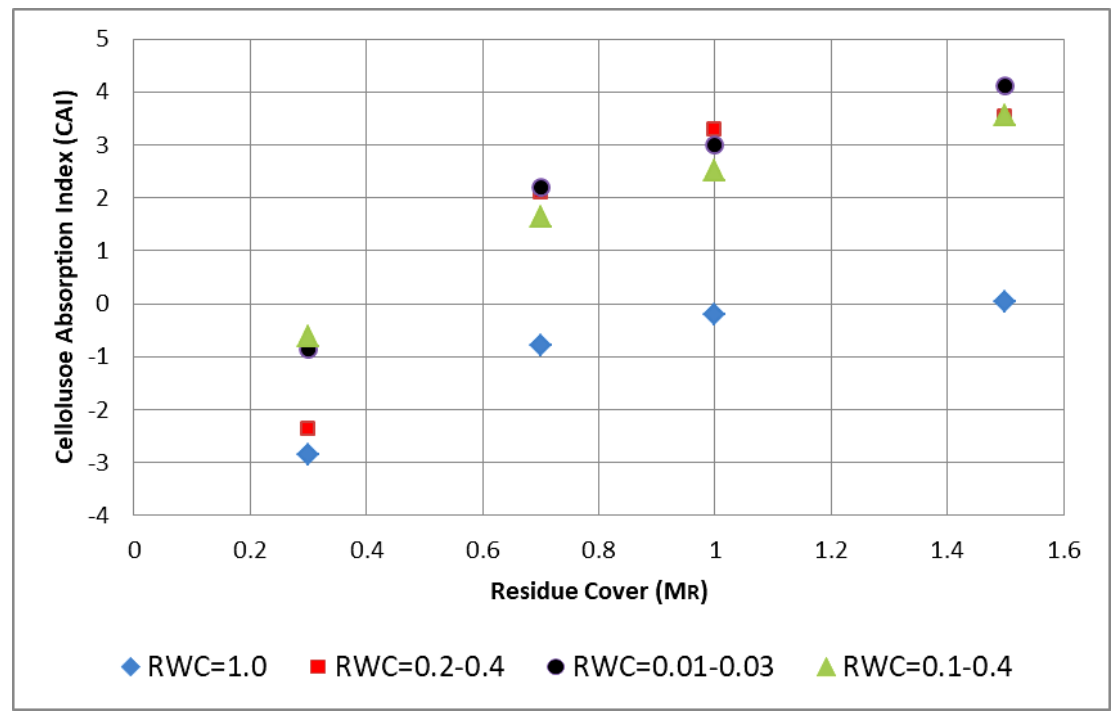

Figure 5 Rice residue cover plotted as a function of CAI for water content ranging from saturated to dry

\begin{tabular}{|c|c|c|}
\hline RWC & $\begin{array}{c}\text { Linear Equation }: y=\text { CAI, } \\
x=\text { Fraction Residue cover }\end{array}$ & $\begin{array}{c}\text { Correlation } \\
\text { coefficient }\end{array}$ \\
\hline 1.0 & $y=2.3185 x-2.9826$ & 0.7945 \\
\hline $0.2-0.4$ & $y=4.7174 x-2.483$ & 0.7528 \\
\hline $0.1-0.3$ & $y=3.3831 x-1.1855$ & 0.9327 \\
\hline $0.01-0.03$ & $y=3.983 x-1.3692$ & 0.8917 \\
\hline
\end{tabular}

Table 1 Correlation coefficients of different water contents 


\section{REFERENCES}

Biard, F., \& Baret, F. (1997). Crop Residue Estimation using Multiband Reflectance. Remote Sensing of Environment, $59,530-536$.

CTIC. (2004). National Crop Residue Management Survey. Conservation Tillage Information Center. West Lafayette: Conservation Technology Information Center. Retrieved from http://www.ctic.org/CRM

Curran, P. J., Dungan, J. L., \& Peterson, D. L. (2001). Estimating the foliar biochemical concentration of leaves with reflectance spectrometry: Testing the Kokaly and Clark methodologies. Remote Sensing of Environment, 76(3), 349-359. http://doi.org/10.1016/S0034$4257(01) 00182-1$

Daughtry, C. S. T. (2001). Discriminating Crop Residues from Soil by Shortwave Infrared Reflectance. Agronomy Journal, 93, 125.

Daughtry, C. S. T., McMurtrey, J. E., Chappelle, E. W., Hunter, W. J., \& Steiner, J. L. (1996). Measuring Crop Residue Cover Using Remote Sensing Techniques. Theoretical and Applied Climatology, 54(1-2), 17-26.

Gausman, H. W., Gerbermann, A. H., Wiegand, C. L., Leamer, R. W., Rodriguez, R. R., \& Noriega, J. R. (1975). Reflectance Differences Between Crop Residues and Bare Soils 1. Soil Science Society of America Journal, 39(4), 752-755.

Lal, R. (1995). The Role of Residues Management in Sustainable Agricultural Systems. Journal of Sustainable Agriculture, 5(4), 51-78. http://doi.org/10.1300/J064v05n04_06

Major, D. J., Larney, F. J., \& Lindwall, C. W. (1990). Spectral Reflectance Characteristics of Wheat Residues. In Proceedings of international geoscience and remote sensing symposium (pp. 603-607).

Mcnairn, H., \& Protz, R. (1993). Mapping corn residue cover on agricultural fields in oxford county, ontario, using thematic mapper. Canadian Journal of Remote Sensing, $19(2)$, $152-159$. http://doi.org/10.1080/07038992.1993.10874543

Morrison, J. E., Huan, C.-H., Lightle, D. T., \& Daughtry, C. S. T. (1993). Residue Measurement Techniques. Journal of Soil and Water Conservation, 48(6), 474838-.

Murray, I., \& Williams, P. C. (1988). Chemical principles of near infrared. In P. Williams \& K. Norris (Eds.), Near infrared technology in the agricultural and food industries (pp. 17-34). St. Paul, Minnesota: American Association of Cereal Chemists, Inc.

Nagler, P. L., Daughtry, C. S. T., \& Goward, S. N. (2000). Plant litter and soil reflectance. Remote Sensing of Environment, 71(2), 207-215. http://doi.org/10.1016/S0034-4257(99)00082-6

Tisdale, S. L., Nelson, W. L., \& Beaton, J. D. (1985). Soil Fertility and Fertilizers. London,UK: Collier Macmillan Publishers. 